\title{
A Comparative Study of the Competitiveness of Nam Dinh Province in the Red River Delta Region of Vietnam
}

\author{
Duong Thi Tinh, Nguyen Thi Thu Ha
}

\section{ABSTRACT}

\begin{abstract}
Before deciding to invest in a certain locality, investors always consider the investment environment or competitiveness of the localities and tend to invest in the localities with the highest scores and high rankings on provincial competitiveness in the region. This study focuses on analyzing and evaluating the competitiveness of Nam Dinh province in comparison with other provinces in the Red River Delta. The results show that although Nam Dinh has made a lot of progress in improving the investment environment and increasing the PCI score, the PCI ranking is still not high, even worse than many other provinces in the region. In order to contribute to improving the province's competitiveness in the coming time, this study has proposed a number of possible solutions.
\end{abstract}

Keywords: Investment Environment, PCI, Provincial Competitiveness, Red River Delta, Vietnam.

\section{INTRODUCTION}

In the context of international economic integration and industrial revolution 4.0, Nam Dinh province is strongly transforming, gradually rising to become the "nucleus" of growth in the South Red River Delta (RRD) region. The province has implemented plans, strategies, and policies of the Government, and at the same time studied, promulgated, and implemented policies on improving the investment environment and enhancing the competitiveness of Nam Dinh province. The efforts of the political system of Nam Dinh province in recent years have achieved certain successes in improving the provincial competitiveness, particularly improving the provincial competitiveness index (PCI), as well as sub-indices of PCI. However, the important of provincial competitiveness is also reflected in the ranking of PCI in the whole country (63 provinces) and in the RRD region (11 provinces, including Nam Dinh). If the province has a good business environment and is more competitive than other provinces, it will be more attractive to investors and attract more investment capital. Investors will look at the PCI scores and PCI rankings of the provinces to decide which locality they will invest their capital in.

From 2015 to 2020, PCI of Nam Dinh province has many fluctuations in both scores and rankings. Although PCI scores have improved in recent years, they are still only in the Fair or Average operating group. The PCI ranking dropped again compared to 2015 in the national rankings as well as the Red River Delta region. In 2020, Nam Dinh's PCI is in the "Mid high" group and ranks 8th out of 11 provinces in the Red River Delta. This shows that the competitiveness of Nam Dinh province is only in the medium level, quite low compared to other provinces in the region. Based on this context, this study focuses on analyzing the current situation of competitiveness of Nam Dinh province through the PCI, with a comparative study with other provinces in the Red River Delta, so that propose some solutions to improve the score as well as the ranking of the province's competitiveness in the coming time.

\section{Methodology}

The study collected and used secondary data from the Vietnam Chamber of Commerce and Industry (VCCI) and the United States Agency for International Development (USAID) and the Department of Science and Technology, Department of Planning and Investment and Statistical Office of Nam Dinh province. Data on PCI and its sub-indexes of Nam Dinh province and other provinces in the Red River Delta have been collected, descriptive statistics through charts, comparative analysis between the years and between the provinces in RRD.

\section{RESUlts AND DISCUSSION}

\section{A. PCI of Nam Dinh Province in the Period of 2015-2020}

In the period of 2015-2020, the PCI of Nam Dinh province has made many improvements, especially continuously increasing from 2016 to 2019. In 2015, the PCI score of the province was 59.62, but by 2016 the index has dropped 1.08 points. Facing such difficult situation of provincial competitiveness, Nam Dinh Provincial People's Committee has issued the plan to improve the Provincial Competitiveness Index (PCI) of Nam Dinh province in the period of 2017-2020 No. 82/KH -The People's Committee on August 23, 2017, in which assessed the results of the implementation of the PCI improvement in Nam Dinh province in 2016, analyzed the limitations in the 
implementation of the improvement of the PCI index, specifying the causes of the shortcomings, since then, a plan to improve the PCI index in 2017 and the following years has been proposed. The political system at all levels of Nam Dinh province in recent years has made great efforts in improving the PCI index, following the guidelines and plans that the province has set, the results show that the province's PCI index constantly increasing from a score of 58.54 (in 2016), up to 61.43 (in 2017), then 63.01 (in 2018) and up to 65.09 (in 2019).

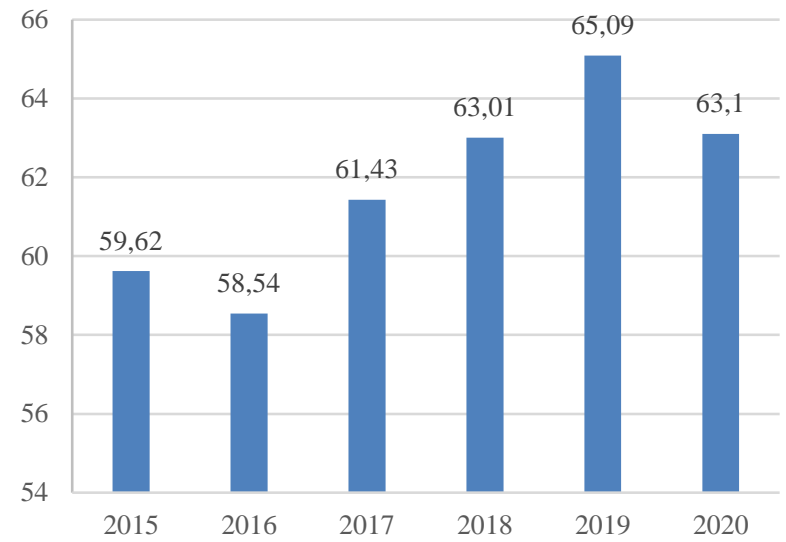

Fig. 1. The fluctuation of Nam Dinh province's PCI, 2015-2020. (Source: VCCI and USAID, 2021).

Although the PCI of Nam Dinh province has improved a lot from 2015 until now, the PCI of the province is still only in the group of good (in 2015, 2016, 2018, 2019) and medium (in 2017 and 2020). In addition, in the context that all provinces and cities in the country are making great efforts to improve the investment environment and enhance PCI, creating strong competition right on the PCI rankings of the country as well as in the region, many provinces and cities have made strong breakthroughs in increasing the PCI index, which has partly affected the PCI ranking of Nam Dinh which has tended to decrease in recent years. In 2015, PCI of Nam Dinh province ranked $17^{\text {th }}$ out of 63 provinces and cities nationwide, ranked $4^{\text {th }}$ out of 11 provinces in the Red River Delta (RRD), but in 2016 and 2017, the PCI ranking dropped sharply, ranked 41/63 and 9/11 (in 2017). By 2018 and 2019, the province had improved in PCI ranking when ranked 33/63 and 7/11 (in 2018). But in 2020, the PCI ranking of Nam Dinh province dropped sharply, ranking $40 / 63$ provinces and cities nationwide and 8/11 provinces in the Red River Delta.
PCI 2020 of Nam Dinh province is analyzed based on data collected from 12,295 enterprises across the country (including: 10,731 private enterprises and 1,564 FDI enterprises). Enterprises are randomly selected stratified in each province and city to ensure the representativeness of all business groups by year of establishment, size, type of ownership and business lines in each local. According to the PCI 2020 ranking report of the Vietnam Chamber of Commerce and Industry (VCCI) in collaboration with the United States Agency for International Development (USAID), the PCI score of Nam Dinh province is 63.10, lower 1.99 points more than in 2019 , down 7 places in the national PCI rankings, 1 place down in the PCI rankings of the Red River Delta. The province's PCI score in 2020 is 0.33 points lower than the national median score (the national median score in 2020 is 63.44 points, 1.69 points lower than the 2019 median score of 65.13 points. points), ranked in the national medium group, ending the uptrend (from 2017 to 2019).

TABLE I: PCI SCORES AND PCI RANKINGS OF NAM DINH PROVINCE,

\begin{tabular}{ccccccc}
\multicolumn{7}{c}{$2015-2020$} \\
\hline Indicators & 2015 & 2016 & 2017 & 2018 & 2019 & 2020 \\
\hline $\begin{array}{c}\text { PCI score } \\
\text { National } \\
\text { rankings } \\
\begin{array}{c}\text { RRD } \\
\text { region }\end{array}\end{array}$ & 59.62 & 58.54 & 61.43 & 63.01 & 65.09 & 63.10 \\
rankings & 4 & 70 & 41 & 35 & 33 & 40 \\
Tier & $\begin{array}{c}\text { Mid- } \\
\text { High }\end{array}$ & $\begin{array}{c}\text { Mid- } \\
\text { High }\end{array}$ & $\begin{array}{c}\text { Mid- } \\
\text { Low }\end{array}$ & $\begin{array}{c}\text { Mid- } \\
\text { High }\end{array}$ & $\begin{array}{c}\text { Mid- } \\
\text { High }\end{array}$ & $\begin{array}{c}\text { Mid- } \\
\text { Low }\end{array}$ \\
\hline
\end{tabular}

(Source: VCCI and USAID, 2021).

\section{B. Analysis on PCI sub-indices of Nam Dinh province}

In the period 2015-2020, among 10 PCI component indexes of Nam Dinh province, the indicators on Informal Charges, Policy Bias, Proactivity, Labor Policy, Law \& Order, Access to Land and Time Costs have much improved. Meanwhile, some other sub-indexes such as Entry Cost, Transparency tended to decrease over the years during this period.

In 2020, Nam Dinh province has 6 PCI sub-indexes that have increased points, which are: Entry Cost $(+0.22)$, Access to Land (+0.3), time costs $(+0,4)$, Informal Charges $(+0.46)$, Policy Bias (+0.64), Law \& Order $(+0.32)$; while some subindices fell: Transparency (-0.72), Proactivity (-0.13), business support services (-0.85), Labor Policy (-0.09).

Among the 10 PCI sub-indices, the Entry Cost index has the highest score, followed by the transparency index and the business support services index. The Policy Bias Index has the lowest score among the 10 sub-indices.

\begin{tabular}{cccccccc}
\multicolumn{7}{c}{ TABLE II: PCI SUB - INDICES OF NAM DINH PROVINCE } \\
\hline PCI sub-indexes & 2015 & 2016 & 2017 & 2018 & 2019 & 2020 & $\begin{array}{c}\text { Increase/decrease } \\
(2020 \text { vs. 2019) }\end{array}$ \\
\hline Entry Cost & 8.53 & 8.58 & 7.62 & 6.49 & 8.23 & 8.45 & 0.22 \\
Access to Land & 6.32 & 5.75 & 6.50 & 6.95 & 6.28 & 6.58 & 0.3 \\
Transparency & 6.06 & 6.06 & 5.33 & 5.42 & 6.55 & 5.83 & -0.72 \\
Time Costs & 6.47 & 6.16 & 6.69 & 7.04 & 6.40 & 6.80 & 0.4 \\
Informal Charges & 4.95 & 5.48 & 4.62 & 6.97 & 5.80 & 6.26 & 0.46 \\
$\quad$ Policy Bias & 4.62 & 5.13 & 5.65 & 5.34 & 6.24 & 6.88 & 0.64 \\
Proactivity & 4.82 & 5.01 & 4.47 & 6.51 & 6.05 & 5.92 & -0.13 \\
Business Support & 5.86 & 5.91 & 6.35 & 6.23 & 6.25 & 5.40 & -0.85 \\
$\quad$ Services & 6.23 & 5.93 & 7.31 & 6.63 & 6.87 & 6.78 & -0.09 \\
Labor Policy & 6.00 & 3.86 & 6.73 & 6.64 & 6.71 & 7.03 & 0.32 \\
Law \& Order & 59.62 & 58.54 & 61.43 & 63.01 & 65.09 & 63.10 & -1.99 \\
PCI score & & & & & & &
\end{tabular}

(Source: VCCI and USAID, 2021). 
60

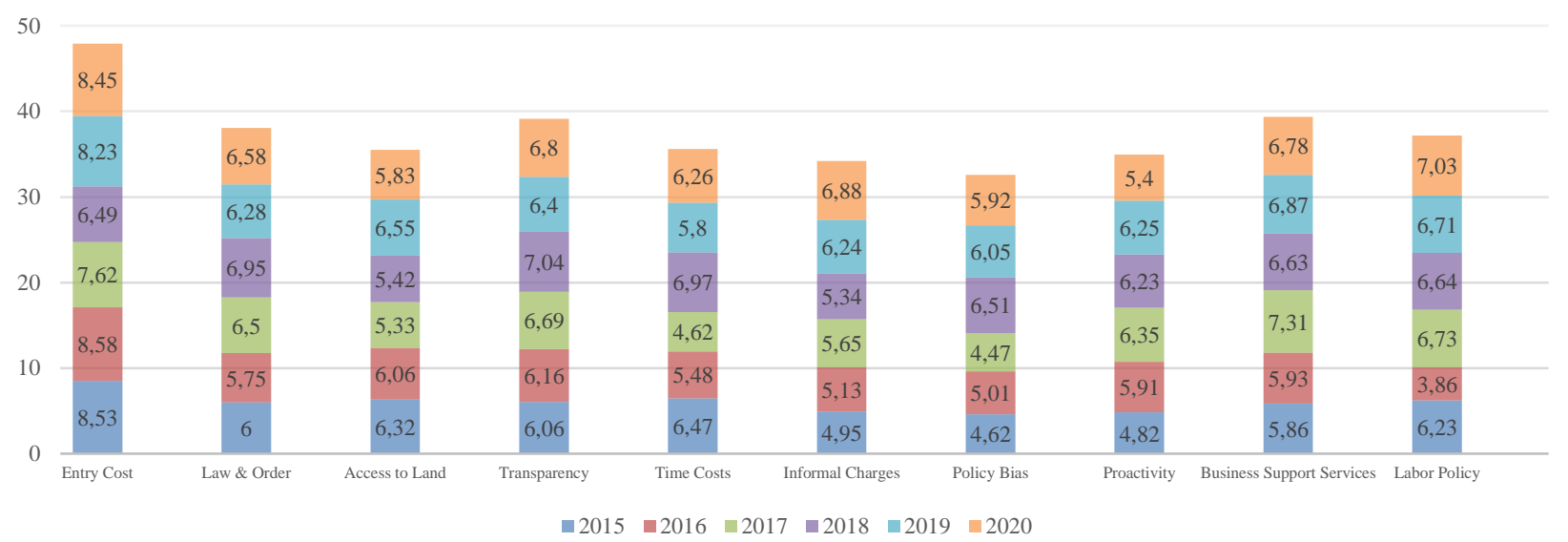

Fig. 2. Overview of movements of 10 PCI sub-indices of Nam Dinh province, 2015-2020. (Source: Author's synthesis and calculations, 2021).

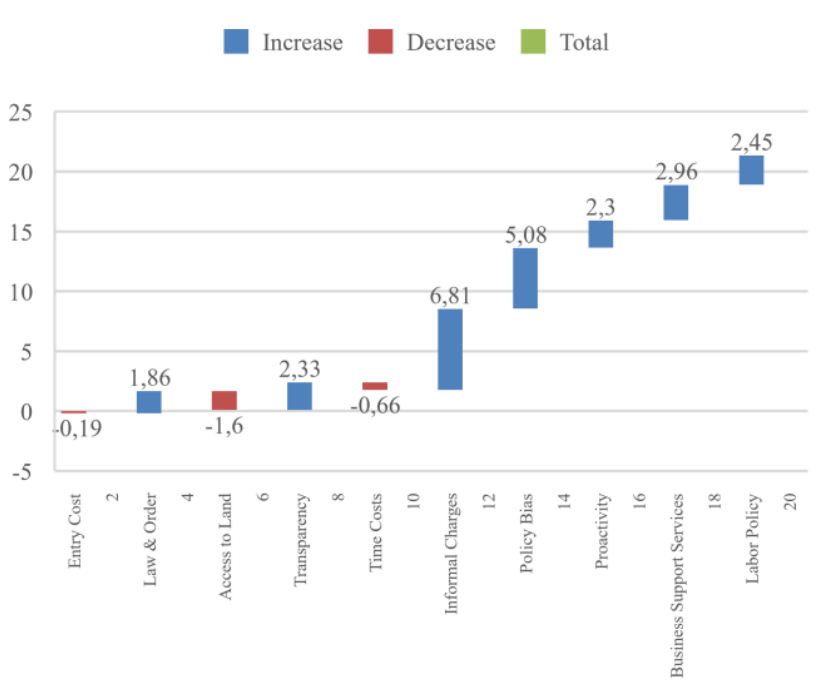

Fig. 3. Growth/Reduction rate of PCI sub-indices of Nam Dinh province, 2015-2020 (\%) (Source: Author's synthesis and calculations, 2021).

For all the years from 2015 to 2020, there were 3 PCI subindices that decreased: Entry Cost index (reduced by 0.19\%), Access to Land index (reduced by 1.6\%) and Time Cost index (reduced by $0.66 \%$ ). While the remaining 7 sub-indexes all increased, the biggest increase was the Informal Charges index (up 6.81\%), the second was the Policy Bias index (up 5.08\%).

The scores of each PCI sub-index over the years in the period 2015-2020 show that although there have been many efforts to improve, it is not stable, sometimes increasing but sometimes decreasing over the years. Most of the PCI subindices of Nam Dinh province in 2020 are only in the level of mid-high and mid-low. This result reflects the limitations existing in the investment environment of Nam Dinh province at present.

\section{The Comparative Analysis on PCI of Nam Dinh Province with Other Provinces in the Red River Delta Region}

According to the PCI report of the Vietnam Chamber of Commerce and Industry (VCCI) in collaboration with the United States Agency for International Development (USAID) for the years 2015-2020, it shows fluctuations in the provincial competitiveness of 11 provinces/cities in the Red River Delta. In the period 2015-2020, if 11 provinces and cities are divided into 3 groups: excellent, high, and mid-high, mid-high and mid-low, there are 5 provinces in the group of mid-high and mid-low, namely Nam Dinh, Thai Binh, and Ha. Nam, Hai Duong, Hung Yen.

\begin{tabular}{ccccccc}
\multicolumn{1}{c}{ TABLE III: PCI OF THE PROVINCES IN THE RED RIVER DELTA, 2015-2020 } \\
\hline Province/City & 2015 & 2016 & 2017 & 2018 & 2019 & 2020 \\
\hline Quang Ninh & 65.75 & 65.6 & 70.69 & 70.36 & 73.4 & 75.09 \\
Hai Phong & 58.65 & 60.1 & 65.15 & 64.48 & 68.73 & 69.27 \\
Ha Noi & 59 & 60.74 & 64.71 & 65.4 & 68.8 & 66.93 \\
Bac Ninh & 59.91 & 60.35 & 64.36 & 64.5 & 70.79 & 66.74 \\
Thai Binh & 57.64 & 57.72 & 61.97 & 63.23 & 65.38 & 64.02 \\
Vinh Phuc & 62.56 & 61.52 & 64.9 & 64.55 & 66.75 & 63.84 \\
Ha Nam & 58.49 & 58.16 & 61.97 & 62.77 & 65.07 & 63.47 \\
Nam Dinh & 59.62 & 58.54 & 61.43 & 63.01 & 65.09 & 63.1 \\
Hai Duong & 58.37 & 57.95 & 60.36 & 60.98 & 63.85 & 62.52 \\
Hung Yen & 55.1 & 57.01 & 59.09 & 60.66 & 63.6 & 62.23 \\
Ninh Binh & 58.51 & 60.14 & 61.86 & 63.55 & 64.58 & 61.98 \\
\hline (Source: VCCI and USAID, 2021). & & & &
\end{tabular}

In recent years, the quality of economic management of localities across the country has maintained a positive trend of improvement compared to previous years. Among 11 provinces and cities in the Red River Delta, Quang Ninh province has always maintained the "champion" position in PCI index, always in the group of very well managed in the period 2015-2020. Some provinces have PCI improved from the mid-high level to the high level such as Hai Phong, Hanoi, Bac Ninh, Vinh Phuc. Meanwhile, the improvement of the PCI index of Nam Dinh province shows that it is still not as strong as other localities, still in the mid-high and mid-low group in the period 2015-2020. The PCI of Nam Dinh province decrease to 63.10 , ranked 8 th out of 11 provinces of RRD in 2020 and returned to the mid-low group after 2 years in the mid-high group.

Although Nam Dinh province's PCI score has only decreased by less than 2 points compared to 2019, the province's PCI ranking has dropped quite far, from the midhigh group across the country (in 2019) to the mid-low group. This further shows the drastic rise of localities on the PCI race, setting requirements for all levels and agencies in the province to be determined to implement practical solutions to overcome existing limitations in the investment environment, thereby in order to improve the PCI, have greater competitiveness for the provinces in the region as well as the whole country. 
operation has increased.

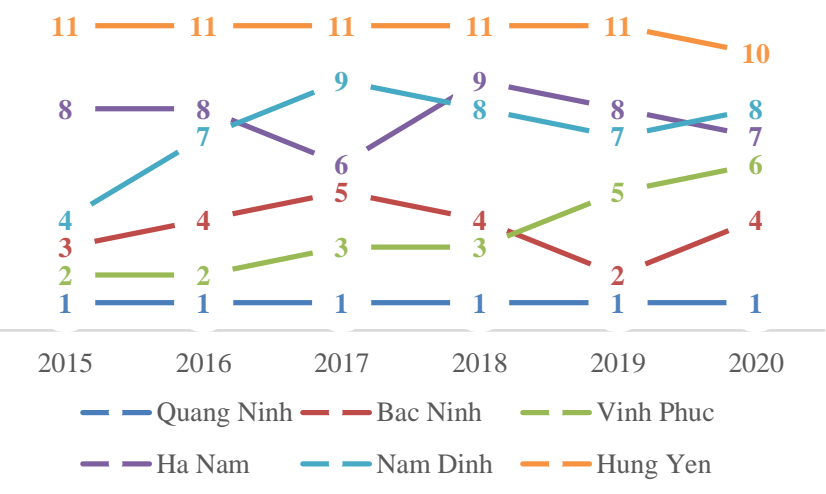

Fig. 4. Comparison of PCI ranking of Nam Dinh province with some other provinces in the Red River Delta, 2015-2020.

(Source: VCCI and USAID, 2021).

\section{Some Limitations in the Competitiveness of Nam Dinh Province}

- The decrease in the total PCI score in 2020 is due to the fact that among the 10 sub-indices, the Business Support Services index and Labor Policy index have a large weight and all decrease by many points.

- The professional qualifications, ethical attitudes, and working styles of civil servants have not satisfied the enterprises. The inspection of public services has not been thorough. The detection and handling of violations had not been timely. There are still acts of abuse of power, abuse of inspection to harass enterprises; There is still a situation of "petty corruption", harassment and trouble for a part of civil servants, especially in the field of land.

- The business support services in the province are still limited in quantity and quality, unable to meet the demand for legal consulting services, accounting and financial training, and business administration, services related to technology, search for market information, search for business partners, trade promotion of enterprises. Therefore, the percentage of businesses that have used business support services is almost the lowest in the country. However, this service quality of private providers is being highly appreciated by the business community.

- The province's main laborers are simple workers in the field of manufacturing textiles, garments, leather shoes, etc., which have not yet met the demand for skilled labor of enterprises. The province's labor level has not caught up with the modern technology trend of the fourth industrial revolution. In addition, there is a lack of linkage between vocational training institutions and job placement service centers with businesses.

- The operational efficiency and quality of the provincial electronic portal as well as the websites of departments, agencies and localities, although improved, still cannot meet the demand for information about planning documents, this is also one of the reasons why businesses have difficulty accessing/expanding business premises. The public listing of fees and charges on electronic portals has not been highly appreciated by enterprises.

- The security and order situation tends to become more complicated. The percentage of businesses that have to pay "protection" for gangsters in order to have peace in their

\section{CONCLUSION AND RECOMMENDATION}

In the period of 2015-2020, Nam Dinh province has made efforts to improve and raise the PCI and sub-indicators. If the PCI index only scored 59.62 in 2015 , the index has improved a lot, in 2020 it has reached a score of 63.1. However, according to the assessment of VCCI and USAID (2020), PCI of Nam Dinh province is still only in the mid-low management group and ranks 8th out of 11 provinces in the Red River Delta. In order to improve the competitiveness of Nam Dinh province in the coming time, some solutions are proposed as follows:

- Actively propagating and improving the responsibilities of civil servants, especially the leaders of official duties. Strengthen inspection of public affairs, promptly detect and strictly handle the situation of harassment and trouble in solving work for citizens and businesses.

- Innovating and improving the quality of business dialogue, completely resolving outstanding opinions on difficulties and problems of enterprises. Enhancing the role of the Association of Small and Medium Enterprises in supporting enterprises to develop production and business, creating conditions for the Association of Small and Medium Enterprises to participate in the implementation of policies to support enterprises.

- Accelerating the implementation of administrative procedure reform, continue to review, simplify, and recommend simplification according to its competence to facilitate, reduce time and costs for people and businesses when entry the market and comply with state regulations.

- Promoting the building of e-government in association with the renovation of the administrative system's operating methods, in line with the process of applying information technology in state management activities. Invest in building the system of Smart City Operation Center in Nam Dinh province after trial operation to meet the requirements of innovation, improve management capacity, quality and efficiency of socio-economic activities.

- Maximizing resources to develop infrastructure for the promotion and attraction of investment. Focusing on speeding up the implementation of infrastructure investment projects in Rang Dong Textile and Garment Industrial Park; Thinh Lam industrial cluster, Giao Thuy district; Yen Duong industrial cluster, Y Yen district; expanding Xuan Tien industrial cluster, Xuan Truong district to attract secondary investors to invest in production and business.

\section{REFERENCES}

[1] Department of Planning and Investment of Nam Dinh Province, Report on the Implementation Status of the Plan No. 91/KH-UBND dated September 25, 2018 of the Provincial People's Committee on improving the Provincial Competitiveness Index (PCI) and Administrative reform index (Par Index) of Nam Dinh province in 2018 and the following years. No. 785/BC-SKH\&DT, June 6, 2019.

[2] Department of Planning and Investment of Nam Dinh Province, Report on Analysis of the Provincial Competitiveness Index (PCI) of Nam Dinh Province in 2019, solutions to improve the PCI Index in 2020 and subsequent years. No. 785/BC-SKH\&DT, June 1, 2020.

[3] Le Thi Thanh Thuy, Pham Thi Thu Huong, Le Van Cuong, "Improving the provincial competitiveness index of Phu Tho province", Journal of 
European Journal of Business and Management Research www.ejbmr.org

Science and Technology, University of Hung Vuong, vol. 17, no. 4, pp. $51-65,2019$.

[4] Nam Dinh Provincial People's Committee, Plan on improving the Provincial Competitiveness Index (PCI) of Nam Dinh Province for the period of 2017 - 2020. No. 82/KH-UBND, August 23, 2017.

[5] Nam Dinh Provincial People's Committee, Plan on improving provincial competitiveness index $(\mathrm{PCI})$ and administrative reform index (Par Index) of Nam Dinh province in 2018 and the following years. No. 91/KH-UBND, September 25, 2018.

[6] Nam Dinh Provincial People's Committee, Plan on the implementation of Resolution No. 02/NQ-CP on January 1, 2019 of the Government on continuing to perform key tasks and solutions to improve the business environment, improving the national competitiveness in 2019 and orientation to 2021 of Nam Dinh province. No. 25/KH-UBND, February 26, 2019.

[7] Ngo Phuc Hanh, Dao Van Hung, Nguyen Thac Hoat, and Dao Thi Thu Trang, "Improving quality of foreign direct investment attraction in Vietnam", International Journal of Quality Innovation, vol. 3, No. 7, pp: 1-16, 2017.

[8] Provincial Competitiveness Index. https://pcivietnam.vn.

[9] Thanh Tung, Diep, "Additional Approaches to Assess the Vietnam Provincial Competitiveness Index (PCI)", International Business Research, vol. 7, No. 3, pp. 1-12, February 2014.

[10] VCCI \& USAID. Vietnam Provincial Competitiveness Index 2015 2020. https://pcivietnam.vn/uploads//VN-Bao-cao-dai-PCI/Bao-caoPCI-2020.pdf. 